\title{
Wallace's Line and the Distribution of Mammals
}

$\mathrm{T}$ HE very definiteness of 'Wallace's Line', which threads its way with precision, though without much apparent geographical reason, between Borneo and Celebes and between the almost contiguous islands of Bali and Lombok, and so marks the boundary between the Oriental and Australian zoogeographical regions, must have raised a doubt in the mind of many a zoologist ; and sometimes the doubt seems to have been justified. In an introduction to the most important analysis which has been made in recent years of the facts of mammalian distribution bearing upon the authenticity of Wallace's boundary*, Dr. W. K. Gregory cites two serious criticisms.

An examination of the fauna of the East Indian Archipelago led P. N. Van Kampen in 1909 to a very definite conclusion. "According to the researches of more recent times, among which should be mentioned especially those of Von Martens, Max Weber and the Sarasins, it becomes evident that such a sharp boundary as Wallace drew does not exist. Not only is there none where he drew it, but no such line exists anywhere in the Archipelago. Of course it is possible to draw such a line which apparently bounds the distribution of some single group; . . . But taking the fauna as a whole it is certain that no line may be drawn; but, rather, we may lay out a transition zone in which the fauna of India and that of Australia are mingled, and wherein from the west to the east the Australian components increase more and more in number; and on the other hand, the Indian tend to die out." Van Kampen regards all the transition region as being essentially linked with the eastern half of the Archipelago, that is with Wallace's "Australian" half, although he insists that even the boundaries of the transition region are not sharply defined.

More recently, W. D. Matthew (1915) proposed. another solution which in effect obliterated Wallace's boundary as the Oriental-Australian divide. He created a new sub-region-AustraloMalaya-which included the islands east of the 'Line', "the debatable ground between the Oriental and the very distinct Australian region", although "the consensus of opinion classes it by preference with the Australian".

Now Henry C. Raven enters the debatable ground and, as the result of a very thorough study of the mammalian fauna, finds new support for the old 'Line'. He has some right to' express an

* Wallace's Line and the Distribution of Indo-Australian Mammals. By Henry C. Raven. Bull. Amer. Mus. Nat. Hist., 78, opinion, for from 1912 until 1918 he collected mammals and other vertebrates in the Dutch East Indies for the United States National Museum, and from 1921 until 1923 he carried on similar collecting in Australia for the American Museum of Natural History. Finally, he has tabulated and mapped the distribution of all the known forms of mammals in the region-2,240 species and subspecies.

The broad fact which has weighed most with critics of 'Wallace's Line' is that many creatures have broken across it in an easterly direction. Raven, therefore, analyses the list of mammals which have transgressed the supposed boundary. His tables and maps are full of suggestive information, and it amounts to this : that the mammals which have crossed in greatest numbers are the bats, shrews, true rats and mice. True squirrels crossed from Borneo to Celebes ; true pigs reached New Guinea ; true deer (Cervus) spread from Java to Celebes, but were also carried about by natives. Indeed, all the transgressions cannot be attributed to natural distribution, for man transported some of the Viverridæ, although Paradoxurus may have drifted over the boundary, and of other Carnivora, while one species of Felis reaches Sumba (not Sunba as in the text, p. 195), the dingo was manborne. The lemur Tarsius and the macaques of Celebes complete the list, except for the greatest mammalian transgressor of all-man.

How does this list stand in comparison with the series of mammals which have found 'Wallace's Line' to be a real boundary? Of the East Indian forms which do not transgress the line, there are the hedgehogs (Erinaceidæ) and tree-shrews (Tupaiidæ) amongst Insectivora, the tree-shrews, with thirty-nine species, reaching Lombok and spreading along the west of the 'Line' to the Philippines ; Galeopithecus; the Spalacidæ ; the squirrels (excluding Sciurus), with eighty-seven species widely distributed west of the 'Line' but none crossing over ; porcupines, hares and rabbits ; the pangolins; amongst the Ungulates, the chevrotains (Tragulus) with forty-three species in the Malayan region, the muntjac deer, tapirs and rhinoceroses have all had their wanderings checked at 'Wallace's Line'. So it is with most carnivora : the dogs (other than the dingo), the single species of bear, and the Mustelidæ, of which eight genera occur in the Malayan region. Apart from the monkeys already mentioned, the Primates keep within the same limits, and they include thirty-six species of semnopitheques, fifteen species of 
Macacus, eight species of gibbons and one highly variable species of orang-all of East Asiatic origin, and none transgressing the 'Line'.

Whatever may be said about the inefficiency of the supposed boundary, it is evident that it has acted as a real barrier to far more mammals and mammalian groups than it has allowed to pass; and, in Raven's words, "this seems consistent with the fact that 'Wallace's Line' for the most part marks the eastern boundary of the ancient continent, while the islands east of it have had only occasional contacts with it. The facts suggest that those numerous families which failed to cross Wallace's Line only reached it in relatively modern times after the barrier was fully established".

Much has been done in the region since Alfred Russel Wallace published his observations and deductions in the sixties and seventies of last century, and the general run of investigation is to suggest that by narrow and temporary land bridges between deep seas, the islands of the Malay Archipelago made occasional contact with the old mainland of Cathaysia. So are explained the abundance of mammalian forms in the Malay Peninsula and Borneo, parts of the old mainland, and the relative scarcity of mammals in Celebes and the Philippine Islands, outliers of the continent. 'Wallace's Line' gains its significance and is a real boundary because it indicates the line of the continental shelf of the old mainland, and that marked the limit of distribution for most East Indian mammals. Van Kampen underestimated the significance of the 'Line', which Raven regards as being "well-established" by the distribution of mammals ; this refers more especially, as Gregory points out, to the southern two-thirds of the 'Line', for the northern end, where it runs south of the Philippines, appears to mark a break of more recent formation and of less zoogeographical significance.

JAMes Ritchie.

\section{Royal Society of Canada}

\section{Annual Meeting}

\section{$\mathrm{T}$} HE Royal Society of Canada held its annual meeting on May 21-24 at MeMaster University, Hamilton, Ontario. The presidential address by Prof. W. Lash Miller dealt with "Some Applications of the Methods of Physical Chemistry to the Study of Micro-organisms". The Flavelle Medal for 1934-35 was presented to Dr. F. T. Shutt, for his numerous contributions in the field of chemistry. The Lorne Pierce Medal was awarded to Dr. E. Montpetit, and the Tyrrell Medal to Brig.-General E. A. Cruikshank.

Prof. L. M. Gould, of Carleton College, Northfield, Minnesota, gave the annual public lecture, his subject being "Adventures in Antarctic Geology". Prof. Gould was a member of the recent Byrd expedition. His lecture was an outstanding humorous presentation of scientific facts.

In Section I (Literature française, Histoire, etc.) eighteen papers were presented, and seventeen in Section II (English Literature, History, etc.). Amongst a number of important contributions might be mentioned that of Dr. Lighthall on a newly discovered Journal of James and Andrew McGill. Besides supplementing greatly the hitherto scanty knowledge of James McGill, the founder of McGill University, this 522-folio-page work gives much information on the affairs of the North-West Fur Company from 1797 until 1814.

The contribution, "De l'influence de la révolu- tion americaine dans la province de Quebec" by Gustave Lanctot, and that by L. W. Howay on "Negro Immigration into Vancouver Island in 1850", served to emphasise the ever-present problem of the influence on Canada of political changes in the United States of America.

The feature of Section III (Mathematical, Chemical and Physical Sciences), which was held under the presidency of Prof. E. F. Burton, wass a symposium on supra-conductivity. Prof. Burton in his presidential address gave a summary of the general phenomena of supra-conductivity. $\mathrm{He}$ was followed by F. G. A. Tarr, who spoke on the magnetic effects in supra-conductors, and announced that he finds the effective permeability to be influenced by the geometrical shape of the body. A. D. Misener gave results of experiments which indicated that the transition point for thin films of lead is a function of the thickness of the film. The results of experimental work done at the cryogenic laboratory at Toronto were summarised, and this was followed by three theoretical papers on the explanation of supraconductivity, by C. Barnes; H. Grayson Smith and Prof. L. V. King. Prof. King's theory, founded on electric polarisation and space lattices, was an important contribution; the theoretical curves for the Wiedemann-Franz relation and the effect of a magnetic field on the transition temperature 